\title{
Absolutely right and relatively good: Consequentialists see bioethical disagreement in a relativist light
}

(Accepted in American Journal of Bioethics- Empirical Bioethics. This is an unedited draft. Please refer to final publication.)

Hugo Viciana ${ }^{\mathrm{a}, \mathrm{b} *}$, Ivar R. Hannikainen ${ }^{\mathrm{a}, \mathrm{c}}$, and David Rodríguez-Arias

a Juan de la Cierva Research Fellow; ${ }^{b}$ Instituto de Filosofía, Consejo Superior de Investigaciones Científicas; ' FiloLab-UGR Scientific Unit of Excellence,Departamento de Filosofía I, Universidad de Granada, Granada, Spain, ${ }^{d}$ Ramón y Cajal Research Fellow

*Hugo.Viciana@normalesup.org, Instituto de Filosofía, Centro de Ciencias Humanas y Sociales, Calle de Albasanz, 26, 28037, Madrid, Spain 
Background: Contemporary societies are rife with moral disagreement, resulting in recalcitrant disputes on matters of public policy. In the context of ongoing bioethical controversies, are uncompromising attitudes rooted in beliefs about the nature of moral truth? Methods: To answer this question, we conducted both exploratory and confirmatory studies, with both a convenience and a nationally representative sample (total $N=1501$ ), investigating the link between people's beliefs about moral truth (their metaethics) and their beliefs about moral value (their normative ethics). Results: Across various bioethical issues (e.g., medically-assisted death, vaccine hesitancy, surrogacy, mandatory organ conscription, or genetically modified crops), consequentialist attitudes were associated with weaker beliefs in an objective moral truth. This association was not explained by domain-general reflectivity, theism, personality, normative uncertainty, or subjective knowledge. Conclusions: We find a robust link between the way people characterize prescriptive disagreements and their sensibility to consequences. In addition, both societal consensus and personal conviction contribute to objectivist beliefs, but these effects appear to be asymmetric, i.e., stronger for opposition than for approval.

Keywords: folk relativism; dissent and disputes; myside bias; utilitarianism; argument evaluation; Spain 


\section{Introduction}

Many bioethical controversies are characterized by disagreement between conflicting moral-ideological groups (Moreno 2005). These disagreements have been linked to differences in cognitive style (Pennycook et al. 2014; Hannikainen et al. 2017), and moral foundations (Mihailov et al. 2020). For instance, reasoning from the moral foundation of purity as opposed to reasoning from the foundation of autonomy can help to explain bioconservatives' greater tendency to view the body as sacred. Disagreements can also be the result of different argumentative processes and reflective thinking styles. Reasoning from certain principles such as medical non-maleficence, or the sanctity of life, can support the prohibition of medically assisted death, while other principles, such as a "right to die" or a "right not to suffer", can support its legalization. Additionally, reasoning about the pros and cons for the different parties involved, as in a form of decision analysis (Baron 2006), can produce yet different conclusions and also yield moral disagreement.

The development of such controversies might be shaped, not exclusively by opposing moral appraisals, but also by people's tacit theories about the nature of morality itself. Such second-order appraisals are sometimes referred to as folk metaethics (Goodwin \& Darley 2008; Zijlstra 2019). They encompass views regarding the scope and universality of first-order moral appraisals, views on the nature of moral disagreement (e.g. objectivist vs. relativist appraisals), the origin of moral norms, or the nature of moral justifications. Different folk metaethical beliefs have been linked to socially relevant outcomes such as tolerance of dissenting others (Collier-Spruel et al. 2019), political polarization (Viciana et al. 2019), motivation for collective action (Young \& Durwin 2013), or the desire for punishment (Rose \& Nichols 2019). 
Relatedly, previous research (Goodwin \& Darley 2010) pointed to a link between 'disjunctive thinking' (a greater willingness to consider alternative possibilities) and a greater tendency toward folk moral relativist positions. Feltz and Cokely (2008) found that high scores in "openness to experience", a personality dimension reflecting one's receptiveness to new things and eschewal of social customs and traditions, correlated with the tendency toward a relativist view of morality. Furthermore, folk perceptions of the divine grounding of moral truth (i.e., divine command theory) are negatively associated with consequentialist reasoning about typically counter-normative acts (such as lying, stealing or killing) (Piazza \& Landy 2013).

Motivated by the above evidence, the present studies examined whether folk perceptions of moral disagreement underlie variations in people's willingness to engage in consequentialist reasoning and offer consequentialist justifications. Consequentialism posits that consequences are the only thing that matters when deciding about morally contested issues. In turn, rejection of consequentialist reasoning in bioethical debates can imply a failure to consider relevant evidence regarding the effects that actions and omissions can have on the various parties affected. A deeper understanding of the dispositions that underlie uncompromising moral attitudes could yield insight into the dynamics that engender persistent and socially disruptive moral disagreement, and in turn render policy disputes irresolvable. Through the lens of various public controversies in bioethics (see Table 1), we examine the link between beliefs about the nature of moral disagreement (i.e, folk metaethical attitudes) and first-order attitudes toward moral value (i.e., folk normative ethics). For all the studies reported in this article, survey materials, data files, and analysis scripts 
can be accessed at the following public repository: https://osf.io/h39pt/. All protocols were approved by the IRB at Consejo Superior de Investigaciones Científicas.

(Table 1 near here)

Table 1. List of bioethical issues employed. 'Animals in entertainment' and 'conscription of cadaveric organs' were only included in study 1 and study 2 respectively.

\begin{tabular}{|l|l|}
\hline Issue & Ethical disagreements (examples) \\
\hline Physician-assisted suicide & Kass \& Lund 1996; Dieterle 2007 \\
\hline Voluntary active euthanasia & Velleman 1992; Singer 2003 \\
\hline Surrogacy & Kirby 2014; Orfali \& Chiappori 2014 \\
\hline $\begin{array}{l}\text { Parents' right not to vaccinate their } \\
\text { children }\end{array}$ & Bradley 1999; Hendrix et al. 2016 \\
\hline Gene editing in humans & Bostrom 2003; Sparrow 2019 \\
\hline $\begin{array}{l}\text { Regulated organ market for } \\
\text { transplants }\end{array}$ & Hippen 2005; Cohen 2013 \\
\hline $\begin{array}{l}\text { GMOs in food } \\
\text { Cognitive enhancement drugs }\end{array}$ & Toft 2012; Russell 2008 \\
\hline $\begin{array}{l}\text { Voluntary abortion } \\
\text { Non-consenting participants in } \\
\text { biomedical research }\end{array}$ & Callahan \& Callahan 1984; Tooley et \\
\hline $\begin{array}{l}\text { Use of human embryos in biomedical } \\
\text { research }\end{array}$ & Baron 2006; Barrett \& Parker 2003 \\
\hline $\begin{array}{l}\text { Mandatory organ conscription for } \\
\text { transplants }\end{array}$ & Meyer 2005 \\
\hline
\end{tabular}




\begin{tabular}{|l|l|}
\hline $\begin{array}{l}\text { Sexual assistance for the severely } \\
\text { disabled }\end{array}$ & Appel 2010; Di Nucci 2011 \\
\hline $\begin{array}{l}\text { Use of animals in entertainment and } \\
\text { traditional festivities }\end{array}$ & Casal 2003; Wolff 2018 \\
\hline Use of animals in biomedical research & $\begin{array}{l}\text { Festing \& Wilkinson 2007; Fiester } \\
2008\end{array}$ \\
\hline
\end{tabular}

\section{Study 1}

The aim of the first study was to test the relationship between folk meta-ethical views on the nature of moral disagreements and consequentialist attitudes toward various controversial practices in bioethics. Guided by previous research uncovering the correlates of consequentialist and metaethical attitudes, Study 1 included a series of additional measures.

First, actively open-minded thinking (AOT) is thinking that allows consideration of different possibilities, different goals, and contravening evidence. Actively open-minded beliefs (e.g. "People should take into consideration evidence that goes against conclusions they favor"; see Baron 2008) encourage more flexible opinion updating in response to relevant information and a more active search for contravening reasons.

Second, the study included an argument evaluation task conceived as a conceptual replication of Stanovich \& West's (1997) work on AOT and myside bias. Myside bias has been characterized as selectively discounting evidence for positions that one does not endorse (Baron 1995). In our study, we examined the contribution of folk metaethical attitudes to variation in myside bias when assessing argumentative replies. Our exploratory analyses of this 
task, which can be found at the online repository, yielded mixed results and

were inconclusive. In what follows we will not concentrate on those and we will

focus on the rest of the measures.

\section{Methods}

\section{Participants}

Participants were recruited through advertisements on two different social media platforms location-targeting users in Spain ${ }^{1}$. The advertisement sought volunteers to take part in a 20-minute academic study on moral intuitions. All participants provided informed consent.

\section{Measures}

Value judgment task. Participants were asked to consider 14 controversial practices in contemporary bioethics and reported their attitude toward each practice on a 6-point, bipolar Likert scale anchored at 1: "Absolutely good" and 6: "Absolutely bad". This task produced two different measures per issue:

\footnotetext{
${ }^{1}$ Spain's Human Development Index increased from 0.755 in 1990 to 0.893 by 2018, having a life expectancy at 83.4 years (2018) and a nominal per capita GDP of $\$ 29,614$ (World Bank, 2019). In the past decade, surveys regularly capture that over $60 \%$ of Spaniards self-identify as 'catholics', but only around $20 \%$ consider religion to be important in their life. Relevant to the issues included in our survey, Spain has had a presumed consent policy for organ transplantation since 1979, by which individuals or family members can opt-out or specify which organs to donate. Transplantation refusal rates by the relatives of the deceased are among the lowest in the world. Physician-assisted death or any recognized form of medical euthanasia were illegal while we collected survey data but also have enjoyed wide public support for over a decade in spite of public opposition by the Catholic church. Laws regulating euthanasia and medically assisted suicide were finally approved in congress while we were correcting the proofs of this article. In the early 2000s, Spain was the first Catholic country in Europe to authorize research on human embryos to obtain stem cells, and national and regional laws regulate the use of human embryos in biomedical research. Surrogacy is illegal in all its forms and is often considered a politically polarizing issue. Our inclusion in study 1 of the use of animals in entertainment was surely interpreted by most participants as referring to the banning of bullfighting and other traditional festivities involving the suffering of animals: several regions in Spain have partially banned these practices.
} 
- 'Valence' was the result of centering value judgments on the scale midpoint (by subtracting 3.5), so that positive (/negative) values indicated favouring (/opposing) the practice.

- 'Extremity', was the result of squaring the valence judgments, and indicated the strength of participants' support or rejection for each practice.

Social norm task. Subjects were asked to estimate the percentage of the national population in favor of allowing each of the 14 practices (e.g. 'In your opinion, what proportion of the Spanish population favors allowing a regulated market for organ donations?'). As with the previous task, we coded two different variables:

- Social norm 'valence', ranging from -50: entirely opposed to 50: entirely in favor, was derived by centering the raw percentage measure to $50 \%$ (i.e., raw percentage - 50).

- Social norm 'consensus', ranging from 0: completely dissensual to 2500: completely consensual, was the result of squaring the social norm valence.

Metaethical judgment task. For each of the issues in Table 1, participants read about a disagreement involving two parties. One person thinks that allowing practice ' $x$ ' is morally acceptable; the other person thinks that allowing practice ' $x$ ' is morally unacceptable. Following a popular paradigm in moral psychology (Heiphetz \& Young 2017; Schmidt, et al. 2017; Beebe 2015), participants were asked whether (a) both parties could be right, (b) at least one of them must be wrong, and were provided (c) a nonresponse option. Selecting 
(a) was coded as a relativist response, and selecting (b) was coded as an objectivist response.

Consequentialism task. Inspired by a previous consequentialist measure (Piazza \& Sousa 2013), participants were asked "Which of the following positions best describes your attitude towards the following issues?”. For each issue (e.g. gene editing in humans for single gene diseases), participants endorsed one of four response options, where options a) and d) reflect categorical preferences and options b) and c) reflect preferences in (conditioned) consequentialist terms (coded as a consequentialist response):

a) "it should never be allowed";

b) "if the consequences are more positive than negative, then it should be allowed";

c) "if the consequences are more positive than negative, then it should be mandatory";

d) "it should always be allowed".

Actively Open-Minded Thinking Beliefs. Participants completed a Spanish translation of the 10-item AOT Beliefs scale (Baron 2019) by rating each item on a 6-point scale from 'Completely Agree' to 'Completely Disagree'.

\section{Results}

After excluding participants who (i) did not complete the survey, who (ii) did not pass a simple attention check, and (iii) whose completion times fell below the minimum bound, an $N$ of 391 was obtained. This online convenience sample 
was composed predominantly of young (mean age $=20.6$ years), female $(82 \%$ women) participants.

Table 2 reports correlations for the constructs in this study, separately by participants (i.e., averaging across issues and comparing participants) and by issues (i.e., averaging across participants and comparing issues).

(Table 2 near here)

Table 2. Pairwise correlations by subjects $(N=391$; below diagonal) and issues ( $i=13$; above diagonal): Study 1. By-subjects correlations were calculated by correlating participant averages across all issues. By-item correlations were calculated by correlating item averages across participants. Objectivism thus refers to mean subjects' responses for each one of the issues to the 'can they both be right' question (above diagonal) and subject's proportion of 'only one can be right' answers to all items (below diagonal). See 'Measures' section for details on coding of the variables.

\begin{tabular}{|c|c|c|c|c|c|c|c|}
\hline & & (1) & (2) & (3) & (4) & (5) & (6) \\
\hline (1) & Valence & - & $\begin{array}{c}.05 \\
{[-.49, .57]}\end{array}$ & $\begin{array}{c}.66^{*} \\
{[.19, .88]}\end{array}$ & $\begin{array}{c}-.33 \\
{[-.73, .24]}\end{array}$ & $\begin{array}{c}.29 \\
{[-.31, .73]}\end{array}$ & $\begin{array}{c}-.36 \\
{[-.75, .21]}\end{array}$ \\
\hline (2) & Extremity & $\begin{array}{c}.17^{* *} \\
{[.07, .26]}\end{array}$ & - & $\begin{array}{c}.15 \\
{[-.41, .63]}\end{array}$ & $\begin{array}{c}.03 \\
{[-.55, .51]}\end{array}$ & $\begin{array}{c}-.77 \text { * } \\
{[-.93,-.37]}\end{array}$ & $\begin{array}{c}.86^{* *} \\
{[.59, .95]}\end{array}$ \\
\hline (3) & Social valence & $\begin{array}{c}.14^{* *} \\
{[.05, .24]}\end{array}$ & $\begin{array}{c}.08 \\
{[-.02, .18]}\end{array}$ & - & $\begin{array}{c}-.73 \text { * } \\
{[-.91,-.32]}\end{array}$ & $\begin{array}{c}.17 \\
{[-.42, .66]}\end{array}$ & $\begin{array}{c}-.28 \\
{[-.70, .30]}\end{array}$ \\
\hline (4) & Consensus & $\begin{array}{c}-.09 \\
{[-.18, .01]}\end{array}$ & $\begin{array}{c}.22^{* *} \\
{[.12, .31]}\end{array}$ & $\begin{array}{c}-.08 \\
{[-.18, .02]}\end{array}$ & - & $\begin{array}{c}.03 \\
{[-.53, .57]}\end{array}$ & $\begin{array}{c}.27 \\
{[-.30, .70]}\end{array}$ \\
\hline
\end{tabular}




\begin{tabular}{lccccccc}
\hline (5) Consequentialism & $\begin{array}{c}.28^{* *} \\
{[.19, .37]}\end{array}$ & $\begin{array}{c}-.41^{* *} \\
{[-.49,-.32]}\end{array}$ & $\begin{array}{c}.07 \\
{[-.03, .17]}\end{array}$ & $\begin{array}{c}-.18^{* *} \\
{[-.28,-.09]}\end{array}$ & $-\begin{array}{c}-.94^{* *} \\
{[-.98,-.80]}\end{array}$ \\
\hline & & $-.19^{* *}$ & $.39^{* *}$ & -.02 & $.18^{* *}$ & $-.38^{* *}$ & - \\
\hline & {$[-.28,-.09]$} & {$[.30, .47]$} & {$[-.12, .08]$} & {$[.08, .27]$} & {$[-.47,-.30]$} & - \\
\hline
\end{tabular}

Extremity and consensus effects on metaethical judgments

Value judgments revealed a parabolic relationship with metaethical beliefs: Both extreme positive and extreme negative value judgments were associated with an objectivist stance, while more moderate judgments were associated with a relativist stance--which we refer to as an extremity effect (see Figure 1). Adding either a quadratic value $\operatorname{term}^{2}(\mathrm{AIC}=5262.8)$ or an absolute value term $(A I C=5277.5)$ improved model fit over the linear model $(\mathrm{AIC}=$ 6291.2), ps $<.001$.

Both models documented an extremity effect, ORs $=3.51,3.55, z s=$ 28.3, 27.7, $p$ s $<.001$. In addition, both models revealed a negative linear effect, ORs $=0.61,0.59, z s=-10.7,-11.4, p s<.001$--indicating greater objectivism for negative than for positive attitudes. Furthermore, the association between extremity and objectivism arose when analyzing each issue separately, all ps $<.001$ (see Figure 1).

Figure 1. Objectivism by value judgment (separately for each issue). Folk objectivist responses are depicted on the $\mathrm{y}$ axis as a polynomial function of value judgments responses about how good or how bad it would be to allow

\footnotetext{
${ }^{2}$ Strictly speaking one could not infer a U-shape exclusively by a quadratic test, as reminded by Simonsohn, 2018. Visual inspection of the data alone, however, tells us that these measures are not linear in ways that are relatively easy to interpret.
} 
each one of the issues. Separate functions are fitted for Study 1 and Study 2, and the $95 \%$ confidence interval is shaded.

(Figure 1 near here)

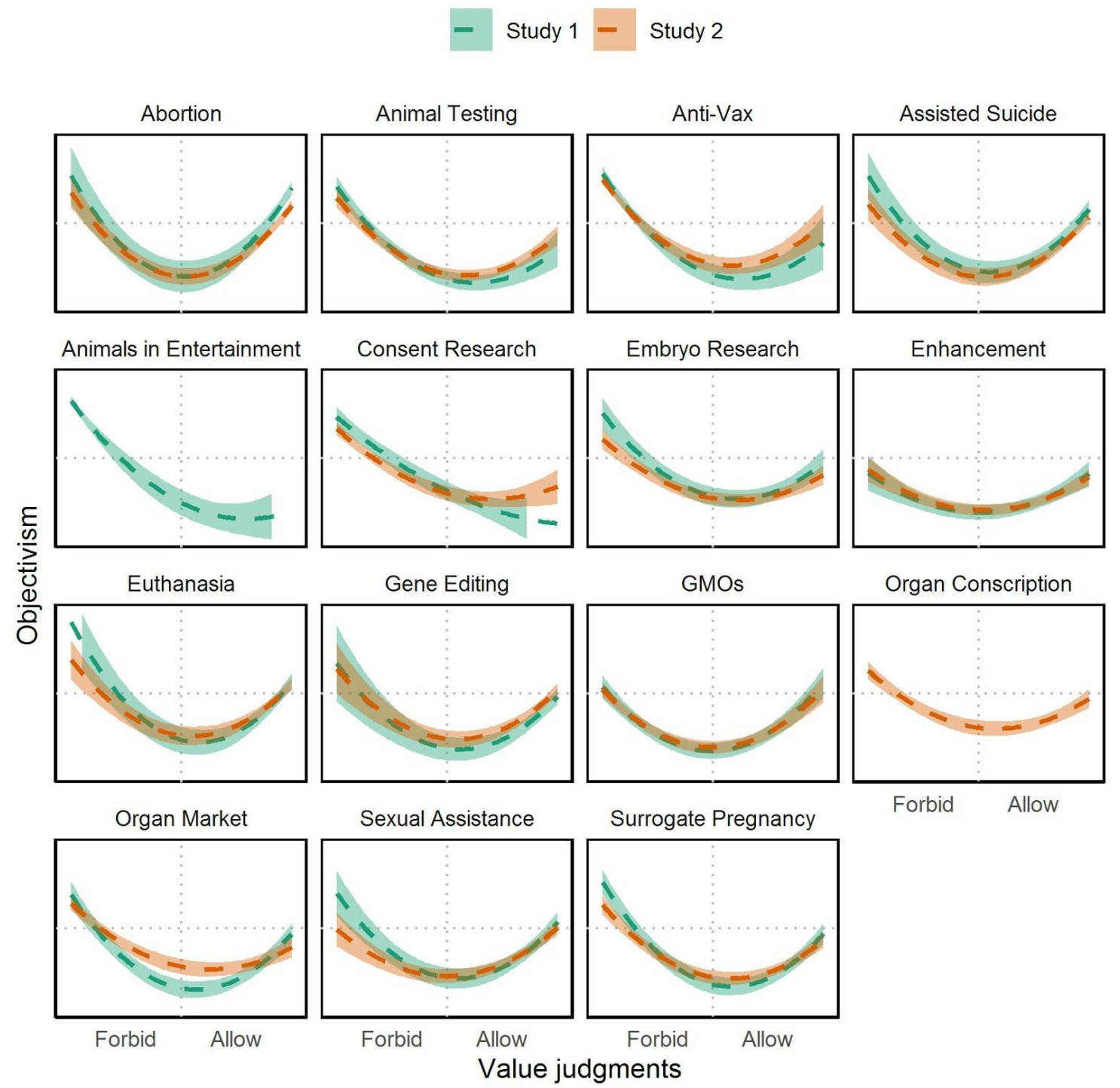

Figure 2. Issue-level objectivism and consequentialism by value judgment. Mean level of consequentialist preferences (top) and mean proportion of objectivist responses (bottom) are depicted as a polynomial function of mean value judgments across each one of the items. Actual aggregated values for each one of the issues are plotted and labelled accordingly. Consequentialism data regarding vaccination reticence were not 
collected in study 1 .

(Figure 2 near here)

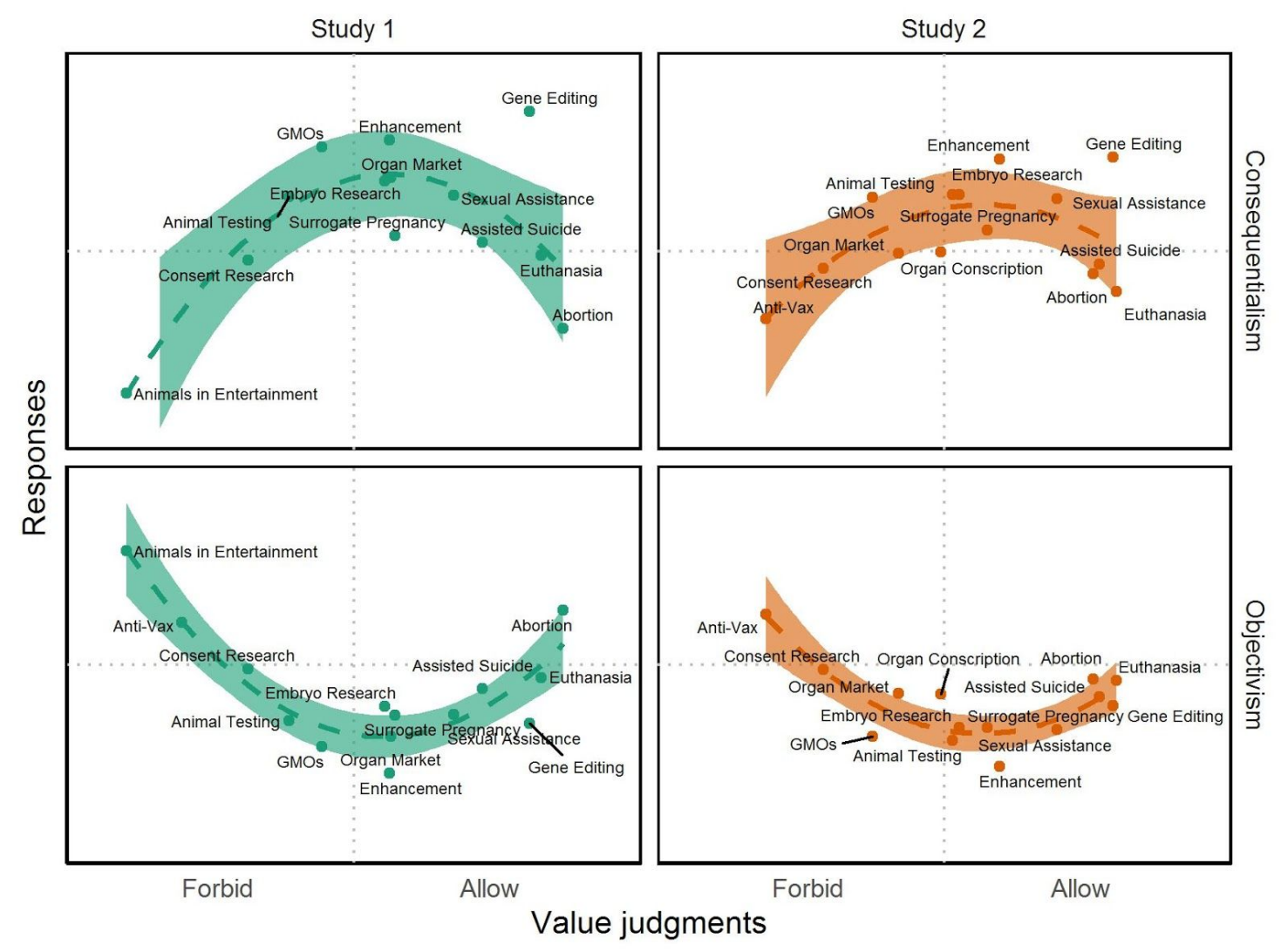

As shown in Table 2, the extremity effect emerged across issues, such that issues eliciting more extreme value judgments were more likely to be viewed as objective ("only one can be right").

Social norm judgments revealed a parabolic relationship with objectivist attitudes: perceived dissensus was linked to relativist attitudes ("both can be right"), while perceived consensus was associated with objectivist attitudes--which we refer to as a consensus effect (see Figure 4). Both a quadratic term $(\mathrm{AIC}=6177.8)$ and a folded term $(\mathrm{AIC}=6180.2)$ captured this 
relationship and improved model fit over the linear model $(A I C=6401.6), p s<$ .001. Entering a cubic frequency term $(\mathrm{AIC}=6164.4)$ further improved model fit by accounting for the steeper slope of negative versus affirmative consensus, $X^{2}(d f=1)=15.3, p<.001$. Critically, every model documented a robust consensus effect, $1.69<$ ORs $<2.42,14.1<z s<14.5, p s<.001$. The effect of consensus, however, was not significant across items, $r=.34,95 \% \mathrm{Cl}[-.23$, .74], $p=.23$ (see Table 2).

Consequentialism and objectivism

As shown in Table 2, consequentialist views were strongly associated with relativist beliefs about disagreement -- both across subjects and across issues. First of all, issues perceived as objective tended to be justified in categorical terms while issues perceived as relative were justified in consequentialist terms, $r(13)=.94,95 \% \mathrm{Cl}[.80, .98], p<.001$. Across subjects, this relationship arose separately on every issue except 'human gene editing' ( $p=.16$; remaining $p s<.001)$, with $\varphi$ s ranging from .07 to .59 . Even when controlling for extremity and consensus effects, the relationship between relativist beliefs and consequentialist responses remained highly significant, OR $=3.18, z=12.82, p<.001$.

The role of cognitive style

To our surprise, AOT scores (Cronbach's $\alpha=.63 ; \mathrm{Mdn}=4.7$ out of 6; IQR: 4.3 to 5.1) did not predict consequentialist choices. In line with previous findings, AOT was however negatively correlated with preference for categorical prohibitions ("it should never be allowed") in the consequentialism task $(r=-.16$, $p=.001)$. Neither did AOT score predict the proportion of folk relativist 
responses given, $r=.00, p=.89$. In sum, greater relativism among consequentialists was unrelated to endorsement of actively open-minded thinking--as AOT predicted neither objectivism nor consequentialism.

\section{Discussion}

Extending past work (Goodwin \& Darley, 2008; Beebe 2014), we found strong effects of extremity and consensus on participants' metaethical beliefs. Furthermore, metaethical beliefs were associated with normative ethical frameworks: Specifically, objectivist beliefs were linked to categorical justifications, while relativist beliefs were linked to consequentialist justifications. This relationship arose both when comparing issues to each other, and individuals to one another. In other words, bioethical practices that tend to be seen as objectively right or wrong were also justified in categorical (i.e., non-consequentialist) terms. Importantly, this association was not explained by differences in the extremity of participants' judgments, or in their perceptions of societal consensus. These findings are exploratory and rest on data from a convenience sample. So, in Study 2 we sought to replicate these results in a representative sample.

\section{Study 2}

Our first study conceptually replicated previous findings (Goodwin \& Darley 2012) showing a link between perceived consensus, extremity and objectivist metaethics, when applied to a range of bioethical controversies. Furthermore, this exploratory study further revealed that folk metaethics can predict whether people offer consequentialist or categorical moral judgments. For our next study, we partnered with a market research company to recruit a 
nationally representative online panel of Spanish adults, aiming to replicate the findings of Study 1.

\section{Methods}

Participants

Members of a nationally representative online panel, sampled through random digit dialing and maintained by the survey research company, were invited to take part in our survey. All participants provided informed consent.

\section{Measures}

The survey was composed of two parts. The first part almost mirrored the first part of Study 1 and included the (1) value judgment and (2) norm tasks, (3) the metaethics task, and (4) an adapted consequentialism task (in which we combined the consequentialist response options). Presentation of issues and dilemmas was randomized for each subject within each block.

Moral dilemmas justification task. In addition, participants completed a new task involving the set of bioethical issues. This time, a series of moral conflicts were more clearly articulated. E.g., a vaccination campaign is described as protecting the population from an epidemic while also causing serious side-effects in some vaccinated children. Another dilemma described a terminally ill patient in full position of their mental faculties who requests medically-assisted suicide, to which their closest relatives vehemently oppose.

Participants were asked whether they judged each of the interventions to be acceptable and to choose one of three different justifications for their judgment: a clearly deontological justification, a clearly consequentialist justification, or a mixed one. 
Individual differences measures. As in Study 1, participants completed a Spanish translation of the Actively Open-Minded Thinking beliefs scale (Baron 2019). In addition, participants completed a Spanish translation of the short Divine Command Ethics scale (based on Piazza and Landy 2013) capturing the extent of agreement with a view of morality based on following God's will and the scriptures.

Demographic measures: age, gender, socioeconomic level and ideological self-identification variables were collected.

Figure 3. Descriptive nation-level statistics: study 2. 'A' and 'B' panels show descriptive item-level data on valence ( "In your opinion, how good or how bad would it be to allow..."); the 'D' panel portrays statistics for perceived social valence for each one of the issues ( "In your opinion what percent of the Spanish population favours allowing ...") while the 'C' panel shows the percent of folk objectivist answers for nationally representative online panel data in study 2. Demographic weights were applied. 
A

A

$$
\begin{array}{r}
\text { Vaccine reticence } \\
\text { Surrogate pregnancy } \\
\text { Sexual assistance } \\
\text { Research without consent } \\
\text { Pharmaceutical enhancement } \\
\text { Organ market } \\
\text { Organ conscription } \\
\text { GMOs } \\
\text { Gene editing } \\
\text { Euthanasia } \\
\text { Embryo research } \\
\text { Assisted suicide } \\
\text { Animal testing } \\
\text { Abortion }
\end{array}
$$

Vaccine reticence urrogate pregnancy -

Research without consent Pharmaceutical enhancement-

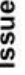

Organ conscription -

Euthanasia

Embryo research

Assisted Suicide -

Animal testing -

Abortion -

$$
\text { Absolutely bad }
$$

Valence

Absolutely good

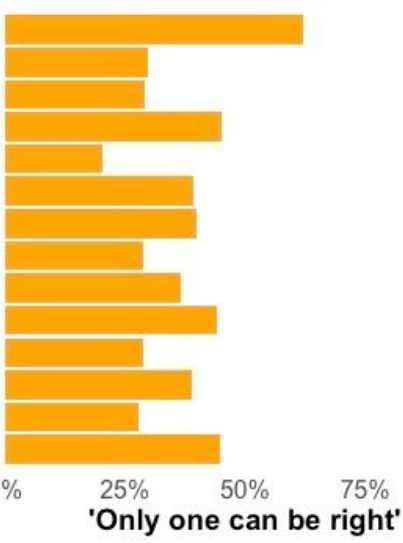

B

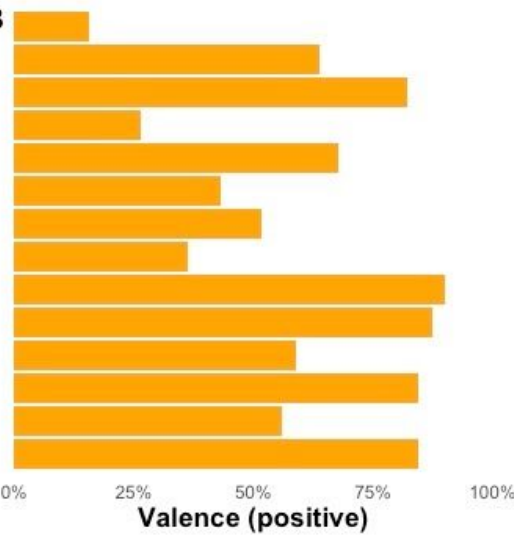

D
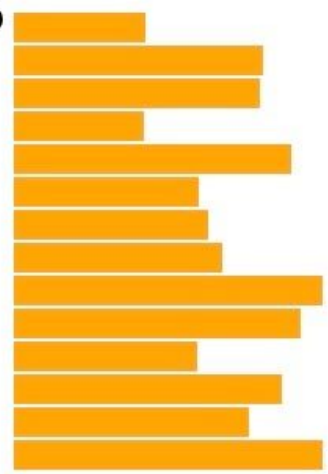

Social norm (perceived)

(Figure 3 near here)

\section{Results}

811 members of the online panel completed our survey. Frequency weights were applied to the final sample, calculated via inverse probability of selection on three demographic parameters: (1) region (seven geographical regions), (2) age-by-sex, and (3) settlement size (five levels, from urban to rural).

Table 3 displays the pairwise correlations for the constructs in Study 2.

(Table 3 near here)

Table 3. Pairwise correlations across subjects ( $N=811$; below diagonal) and issues ( $i=14$; above diagonal): Study 2 . By-subjects correlations (below 
diagonal) were calculated by correlating participant-level measures averaged across the 14 issues. By-item correlations (above diagonal) were calculated by correlating item-level measures after averaging across participants.

\begin{tabular}{|c|c|c|c|c|c|c|c|c|}
\hline & & (1) & (2) & (3) & (4) & (5) & (6) & (7) \\
\hline (1) & Valence & - & $\begin{array}{c}.12 \\
{[-.44, .61]}\end{array}$ & $\begin{array}{c}.92 * * \\
{[.76, .97]}\end{array}$ & $\begin{array}{c}-.71 * \\
{[-.90,-.28]}\end{array}$ & $\begin{array}{c}.26 \\
{[-.32, .69]}\end{array}$ & $\begin{array}{c}-.32 \\
{[-.73, .25]}\end{array}$ & - \\
\hline$(2)$ & Extremity & $\begin{array}{c}.166^{* *} \\
{[.09, .22]}\end{array}$ & - & $\begin{array}{c}.05 \\
{[-.49, .57]}\end{array}$ & $\begin{array}{c}.38 \\
{[-.19, .76]}\end{array}$ & $\begin{array}{c}-.78^{* *} \\
{[-.93,-.42]}\end{array}$ & $\begin{array}{c}.85 * * \\
{[.59, .95]}\end{array}$ & - \\
\hline (3) & Social valence & $\begin{array}{c}.38 * * \\
{[.32, .44]}\end{array}$ & $\begin{array}{c}.07^{*} \\
{[.00, .14]}\end{array}$ & - & $\begin{array}{c}-.76 * \\
{[-.92,-.39]}\end{array}$ & $\begin{array}{c}.35 \\
{[-.22, .74]}\end{array}$ & $\begin{array}{c}-.41 \\
{[-.77, .15]}\end{array}$ & - \\
\hline (4) & Consensus & $\begin{array}{c}-.04 \\
{[-.11, .03]}\end{array}$ & $\begin{array}{c}.32 * * \\
{[.26, .38]}\end{array}$ & $\begin{array}{c}-.08^{*} \\
{[-.14,-01]}\end{array}$ & - & $\begin{array}{c}-.49 \\
{[-.81, .06]}\end{array}$ & $\begin{array}{c}.72 * * \\
{[.31, .91]}\end{array}$ & - \\
\hline (5) & Consequentialism & $\begin{array}{c}.07^{*} \\
{[.00, .14]}\end{array}$ & $\begin{array}{c}-.43^{* *} \\
{[-.49,-.37]}\end{array}$ & $\begin{array}{c}.04 \\
{[-.03, .11]}\end{array}$ & $\begin{array}{c}-.29 * * \\
{[-.35,-.22]}\end{array}$ & - & $\begin{array}{c}-.866^{* *} \\
{[-.96,-.61]}\end{array}$ & - \\
\hline (6) & Objectivism & $\begin{array}{c}-.05 \\
{[-.11, .02]}\end{array}$ & $\begin{array}{c}.33^{* *} \\
{[.27, . .39]}\end{array}$ & $\begin{array}{c}.00 \\
{[-.07, .06]}\end{array}$ & $\begin{array}{c}.24^{\star *} \\
{[.17, .30]}\end{array}$ & $\begin{array}{c}-.40 * * \\
{[-.45,-.34]}\end{array}$ & - & - \\
\hline (7) & AOT score & $\begin{array}{c}.11^{\star *} \\
{[.04, .17]}\end{array}$ & $\begin{array}{c}.17^{\star *} \\
{[.10, .24]}\end{array}$ & $\begin{array}{c}.02 \\
{[-.05, .09]}\end{array}$ & $\begin{array}{c}.05 \\
{[-.02, .11]}\end{array}$ & $\begin{array}{c}.01 \\
{[-.06, .08]}\end{array}$ & $\begin{array}{c}-.03 \\
{[-.10, .04]}\end{array}$ & - \\
\hline (8) & $\begin{array}{l}\text { Divine command } \\
\text { ethics }\end{array}$ & $\begin{array}{l}-.26 \text { ** } \\
{[-.32} \\
-.20]\end{array}$ & $\begin{array}{c}-.12 * * \\
{[-.19,-.05]}\end{array}$ & $\begin{array}{c}-.01 \\
{[-.08, .06]}\end{array}$ & $\begin{array}{c}-.04 \\
{[-.11, .03]}\end{array}$ & $\begin{array}{c}.08 * \\
{[.01, .15]}\end{array}$ & $\begin{array}{c}-.03 \\
{[-.10, .04]}\end{array}$ & $\begin{array}{l}-.35^{* *} \\
{[-.41,-.29]}\end{array}$ \\
\hline
\end{tabular}

Extremity and consensus effects on metaethical intuitions

Replicating Study 1, value judgments revealed a parabolic relationship with objectivist attitudes: neutrality was linked to relativist attitudes, while both positive and negative value judgments were associated with an objectivist stance. 
Once again, both a quadratic value term $(\mathrm{AIC}=11562)$ and a folded value term $(\mathrm{AIC}=11605)$ improved model fit over the linear model $(\mathrm{AIC}=$ 12858), $p<.001-$ thereby documenting the extremity effect, ORs $=2.67,2.65$, $z s=33.3,32.5, p s<.001$. In addition, both models revealed a negative linear effect, ORs $=0.72,0.69, \mathrm{zs}=-11.1,-12.2, p s<.001-$ indicating that the extremity effect was larger for negative than for positive value judgments.

Replicating Study 1, social norm judgments revealed a parabolic relationship with objectivist attitudes: dissensus was linked to relativist attitudes, while perceived consensus was associated with an objectivist stance. Both a quadratic term $(\mathrm{AIC}=12465)$ and an absolute value term $(\mathrm{AIC}=12464)$ improved model fit over the linear model $(\mathrm{AIC}=12968), p<.001$. As in Study 1 , entering a cubic term $(A I C=12456)$ further improved model fit by accounting for the steeper slope of negative versus affirmative consensus, $X^{2}(d f=1)=$ $15.3, p<.001$. Critically, every model documented a robust consensus effect, $1.79<$ ORs $<2.43,21.3<z s<21.9$, ps $<.001$. This time, the consensus effect also emerged in a by-item analysis, $r(14)=.78, p<.001$.

Figure 4. Objectivism by social norm judgment (separately for each issue). Folk objectivist responses are depicted on the y axis as a polynomial function of social norms judgments. Separate functions are fitted for Study 1 and Study 2 , and the $95 \% \mathrm{Cls}$ are shaded.

(Figure 4 near here). 


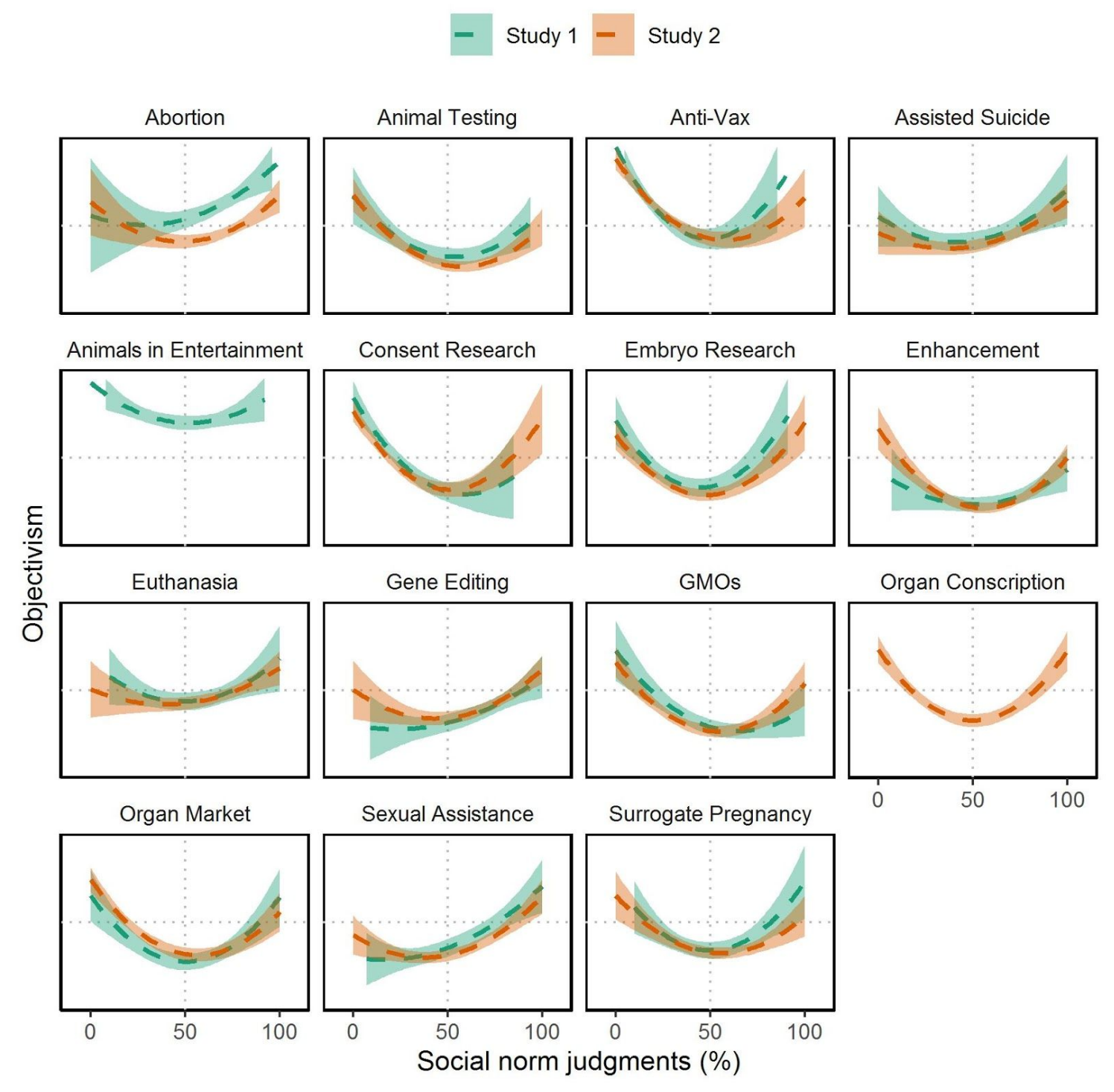

Figure 5. Issue-level objectivism by social norm judgment. Mean folk objectivist responses are depicted on the y axis as a polynomial function of mean social norms judgments and $95 \% \mathrm{Cls}$ are shaded. Actual mean values are plotted for study 1 and study 2 .

(Figure 5 near here) 


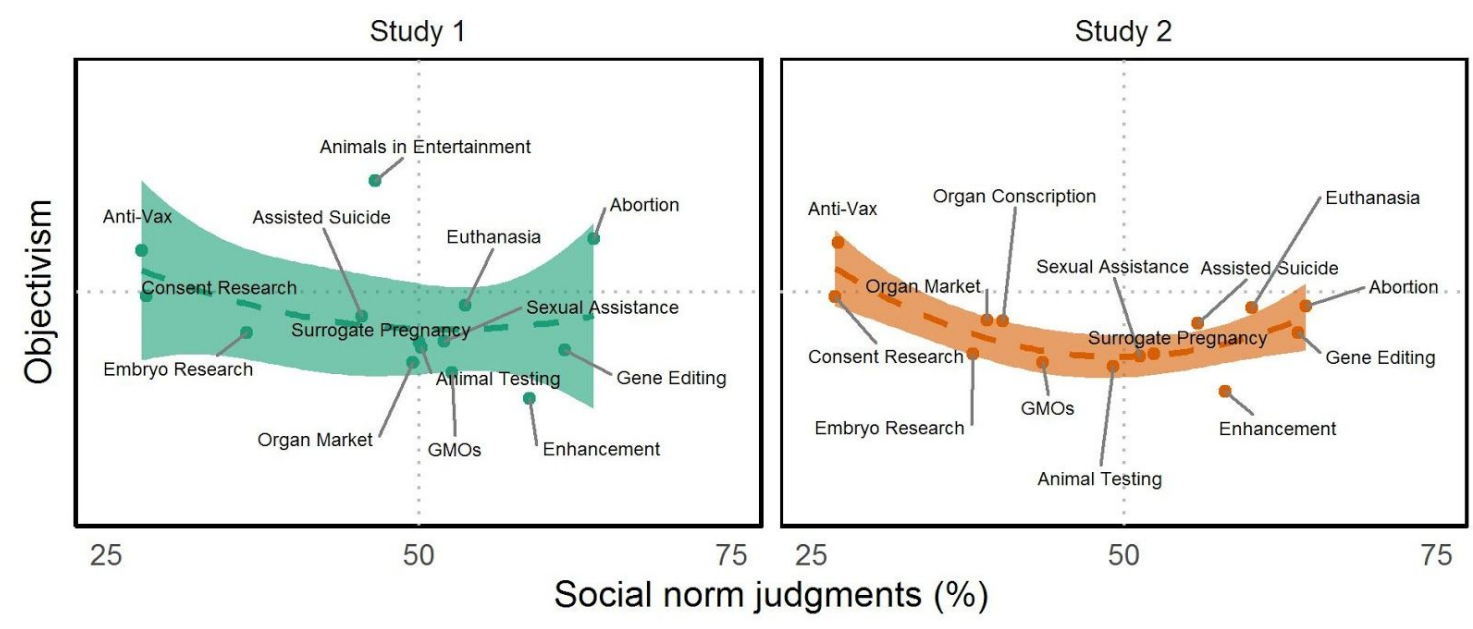

Figure 6. Consequentialism by value judgment (separately for each issue).

Consequentialist preferences toward regulation are depicted on the $y$ axis as a polynomial function of value judgment for study 1 and study $2.95 \% \mathrm{Cls}$ are shaded.

(Figure 6 near here) 


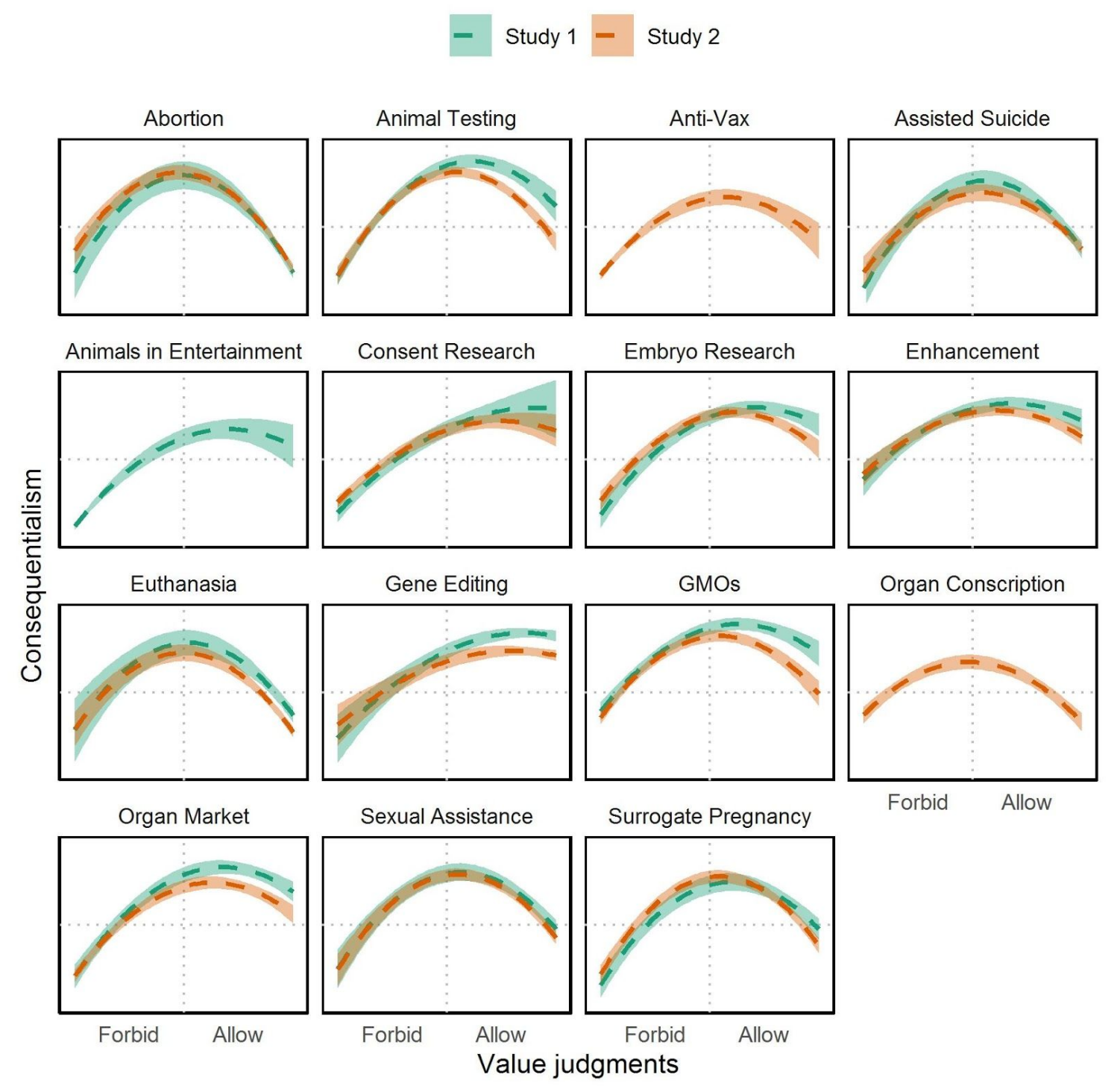

When combining the value and social norm terms in a single model (AIC $=11370)$, we find that these effects are largely independent, supporting the conclusion that both personal extremity and social consensus inform people's metaethical beliefs.

\section{Consequentialism and objectivism}

Study 2 also successfully replicated our novel finding in Study 1. Consequentialist views were strongly associated with relativist beliefs about disagreement, $\mathrm{OR}=0.23, z=-24.6, p<.001$. Once again, as shown in Table 3, this effect arose whether comparing the proportion of objectivist responses by 
participants, $\varphi(811)=-.40$, or by issues, $r(14)=-.86$, both $p s<.001$.

Furthermore, relativist responses predicted consequentialist preferences toward each of the issues considered separately, with correlation coefficients ranging between $\varphi(777)=.17$ and $\varphi(780)=.50$. Importantly, even after controlling for the extremity of value judgments, partial correlations between folk relativist responses and consequentialist preferences remained significant, with partial $r$ s ranging from $r(779)=.18$ to $r(782)=.38$ all $p<.001$.

Actively open-minded thinking. In line with previous studies (e.g. Baron et al. 2015), AOT scores (Cronbach's $\alpha=.63$; $\mathrm{Mdn}=4$ out of 5 ; IQR: 3.6 to 4.4 ) and Divine Command Ethics (Cronbach's $\alpha=.89$; Mdn = 1 out of 5; IQR: 1 to 1.7) were negatively correlated $r(811)=-.35, p<.001$. Yet, as in Study 1 , we obtained no evidence that actively open-minded thinking helps to explain the association between metaethical beliefs and consequentialist preferences. Though AOT scores were positively correlated with the proportion of relativist responses this time, $r(811)=.08, p=.01$, they were unrelated to consequentialist preferences, $r(811)=.01, p=.82$. As in Study 1 , however, looking specifically at categorical prohibitions in the consequentialism task, we did observe a negative relationship between AOT scores and the tendency to select categorical prohibitions, $r(811)=-.08, p=.02$.

Does the relationship between consequentialism and folk moral relativism extend beyond the previously analysed contingencies? In order to answer that question, we examined responses to the novel set of dilemmas. Examining participants' justifications to each of the dilemmas separately showed weak associations between folk relativist intuitions and choosing strictly consequentialist justifications ("The consequences overall for the affected parts 
would be better that way"), over either deontological or hybrid justifications. Mean correlation was $\varphi=.05$. Positive associations ranged from a non-significant $\varphi=.02, p=.40$, to $\varphi=.24, p<.001$; Out of the 14 dilemmas involving conflict between opposing values, only dilemmas dealing with mandatory vaccination ( $\varphi=-.06, p=.05)$, germ-line human genetic editing $(\varphi=$ $-.07, p=.03)$ and mandatory pharmaceutical enhancement $(\varphi=-.07, p=.04)$ showed the reverse association between the relativist response and consequentialist justifications.

In a mixed-effects logistic regression model with random intercepts for participant and dilemma, we regressed the binary variable of adopting a strictly consequentialist justification on issue-specific relativist intuitions as a fixed effect. When simultaneously modeling participant and issue variance in this model, relativist intuitions significantly predicted consequentialist justifications, OR: $1.5295 \% \mathrm{Cl}[1.371 .67], z=8.36, p<.001$. Furthermore, the effect was robust (OR: 1.34, $z=5.67, p<.001)$ to the inclusion of moral extremity in the model, a strong negative predictor of consequentialist justifications in this second model.

\section{Discussion}

Study 2 clearly replicated the findings obtained in our exploratory Study 1 , showing that they generalize from a convenience sample to a more diverse, nationally representative sample. Relativist intuitions once again strongly predicted participants' adherence to consequentialist principles, when considering whether to allow or forbid a series of bioethically contentious practices. In addition, we conceptually replicated this link when measuring preferences for consequentialist justifications using a novel set of bioethical 
dilemmas. Unexpectedly, however, the robust association between relativist intuitions and consequentialist ethics was unexplained by two documented correlates of utilitarian reasoning, namely, religiosity and actively open-minded thinking.

Prima facie, participants holding relativist intuitions in our study are endorsing the description of a situation, which is presented to them as two persons holding contradictory moral claims ("morally acceptable" vs. "morally unacceptable"), as one where a form of non-exclusionary disagreement rules. But how relativistic is it really? Accepting that two simultaneous seemingly contradictory moral judgments 'can be right' can also be interpreted as a form of contextual relativism (both can be right regarding the circumstances), instead of a more canonical form of relativism such as extreme subjectivism, by which the folk may hold that an action is morally right or wrong simply if individuals who judge it this way are of the opinion that it is right or wrong. Perhaps the study of the moral psychology of different dimensions of relativism can inform us on this point. Does the association between consequentialism and folk relativism extend to other more canonical measures of relativistic beliefs? In Study 3, we pursue this question and further explanations (higher social desirability, increased reflection, or epistemic and normative uncertainty) which could link folk metaethical beliefs to first-order normative ethics.

\section{Study 3}

Study 3 had three primary aims. First, we sought to understand whether consequentialist preferences and metaethical intuitions can be explained by way of further third variables (such as social desirability or epistemic uncertainty 
about the issues). In principle, a desire to appear friendly, considerate, and a reliable social partner could undergird people's acceptance that both parties could be right in front of a radical disagreement. Similarly, the subjective sense of epistemic or moral uncertainty surrounding the precise issues in question could also give rise to greater relativist attitudes.

Second, our study sought to disambiguate the particular metaethics that accompanied consequentialist responding in Studies 1 and 2. In particular, Studies 1 and 2 documented that participants often thought two people 'could' both be right in the face of a contradiction about a particular issue $i$. This modal statement is open to distinct interpretations, ranging from the assertion that it is possible for both parties to be right about the same instance of $i$ equipped with all the same facts (i.e., subjectivism), or simply that both parties can be right if they are pointing to different background conditions of $i$ (i.e., contextualism). To glean insight into this question, we adapted the metaethical task to include both modal ('can be right') and non-modal ('are/is right') options. To this end, we also added a further measure of metaethical beliefs (Zilstra 2019).

\section{Methods}

\section{Participants}

Participants were recruited from an online survey platform and took part in exchange for small monetary compensation. All participants provided informed consent.

Measures

As in the previous studies, we included a Metaethical judgment task and a Consequentialism task. This time only 7 items were included (Medically 
assisted suicide; GMOs in food; Biomedical research without consenting patients; Regulated market for non-vital organs; Therapeuting gene editing; Use and destruction of human embryos in biomedical research; Mandatory Organ conscription for the deceased;) Moreover, the Metaethical judgment task included this time several response options from which participants were asked to choose the one that best describes their views on the disagreement: "both can be right', 'only one can be right', and also the strictly subjectivist option 'both are right', an 'only one is right' option, and an 'error' option: 'none of them is right'. Below we report two kinds of analyses where we first code "Both are right" and "Both can be right" as relativist responses and "only one can be right" and "only one is right" as objectivist responses, and test for the replication of the previous results. Afterwards we report exploratory analyses making a finer distinction between the modal relativist "both can be right" responses and non-modal subjectivist responses ("both are right"), the modal objectivist "only one can be right" responses and non-modal absolutist responses ("only one is right").

As before, we included the Spanish translation of AOT beliefs scale (Baron 2019). This time, in addition we also included:

- Moral uncertainty task: A block of questions purporting to capture metacognitive feelings about the endorsement or prohibition of each one of the issues: "How confident or insecure do you feel about the issue of whether or not to allow ' $X$ '?"

- Epistemic uncertainty task: A block of questions asking participants to rate their level of knowledge about the different issues: "In your opinion, how much do you know regarding each of these topics? Much? Just a little bit? Please answer from 1 to 6 , where "1 = Practically nothing at all" and "6 = Very much". 
- Folk moral objectivism scale (Zijlstra 2019). 20-item scale measuring different facets of trait folk moral objectivism (FMO), including belief in independent moral truths, support for universalism/absolutism in morals, and endorsement of divine command ethics.

Finally, half of participants received one of the two following:

- Cognitive reflection task. Three of the original arithmetic items of Fredericks' Cognitive Reflection (CRT) test (Frederick 2005) aiming to capture the ability to override initial responses on further reflection. It included items such as " $A$ bat and a ball cost $\$ 1.10$ in total. The bat costs a dollar more than the ball. How much does the ball cost?"

- Agreeableness and Openness to experience subscales of the Big Five Inventory (John et al. 1991). The agreeableness dimension has been linked to greater social desirability (Graziano \& Tobin 2002) and to the strategic resolution of interpersonal conflicts (Graziano et al. 1996; Campbell \& Graziano 2001).

\section{Results}

After excluding participants based on repeated participation or implausible completion times, we obtained a total $N$ of 299.

As before, items that evoked more objectivist ("only one can be right", "only one is right") responses clearly accompanied weaker consequentialist ethics, $r(7)=-.89,95 \% \mathrm{Cl}[-.98,-.43], p<.01$. Again, individual differences in consequentialist responding predicted relativist responses, $r(299)=.35$, $p<.001$-also when looking at the issues separately ( $\varphi$ s ranging from .19 to .41 all $p s<.001)$.

We then evaluated a series of potential mechanisms by examining 
patterns of association with social desirability, cognitive reflection, moral uncertainty and epistemic uncertainty. Could the link between consequentialist answers and relativist intuitions be explained merely by general personality differences? To the contrary, agreeableness scores $(\alpha=0.69)$ were unrelated to either consequentialism or relativism, as were openness to experience scores $(\alpha=.80)$. Differences in cognitive reflection, as measured by CRT scores, were also uncorrelated with tendencies toward relativist metaethics or consequentialist responses, all ps>.05.

Are relativist and consequentialist responses explained by a lack of epistemic or moral confidence? We let participants the choice of answering that "both are right" instead of "both can be right". In fact, excluding highly subjectivist answers ('both are right') did not augment the coefficients of determination between relativist answers and consequentialist ones --as would have been expected if a penchant for answering 'both can be right', and preferring consequentialist options was just a result of individual uncertainty-but actually decreased those coefficients slightly, $r(299)=.33, p<.001, \varphi \mathrm{s}$ ranging from $\varphi=.15$ to $\varphi=.34$, $p$ s <.001. In a by-participant analysis, mean epistemic uncertainty $(\alpha=.0 .88)$, was a weak predictor of proportion of consequentialist responses $r(299)=.15, p=.006$. Looking at issues separately, only consequentialist answers to GMOs $\varphi=.23, p<.001$ and GeneEditing $\varphi=.11$, $p=.04$ seemed to be affected by the subjective epistemic uncertainty surrounding the issues. In turn, the association between epistemic uncertainty and relativist responses was marginally significant, $r_{\mathrm{pb}}=.11, p=.06$ (and in fact attained statistical significance when predicting 'both can be right' responses ${ }_{\mathrm{pb}}$ $=.17, p=.004$, but not 'both are right', or subjectivist, responses). In contrast, participants' reports of moral uncertainty $(\alpha=.0 .81)$ did not predict their tendency toward relativist, $r(299)=-.02, p=.78$, nor consequentialist responses, $r(299)=$ $-.00, p=.99$. Thus, whereas moral uncertainty appeared to play no role, 
participants' sense of epistemic uncertainty predicted some variance in both metaethical relativism and consequentialist ethics.

Our adaptation of the metaethical judgment task in Study 3 yielded novel insight into the metaethical correlates of consequentialism. Participants gravitated toward the non-modal absolutist option (prop. $=.39,95 \% \mathrm{Cl}[.33$, $.44]$ ), and the modal relativist option (prop. $=.34,95 \% \mathrm{Cl}[.29, .40]$ ), but not the remaining options (modal objectivist: .17, 95\% Cl [.14, .22]; non-modal subjectivist: .06 , 95\% Cl [.04, .10]; and error: .04, , 95\% Cl [.02, .06]).

Furthermore, the two predominant responses, i.e., 'only one is right' and 'both can be right', were associated with categorical ( $p_{\text {Categoricallobjectivist }}=.62,95 \%$ $\mathrm{Cl}[.52, .72], z=11.51, p<.001)$ and consequentialist $\left(p_{\text {Consequentialist } \mid \text { Relativist }}=.79\right.$, $95 \% \mathrm{Cl}[.70, .85], z=11.85, p<.001)$ judgments respectively, as shown in Figure 7.

(Figure 7 near here) 


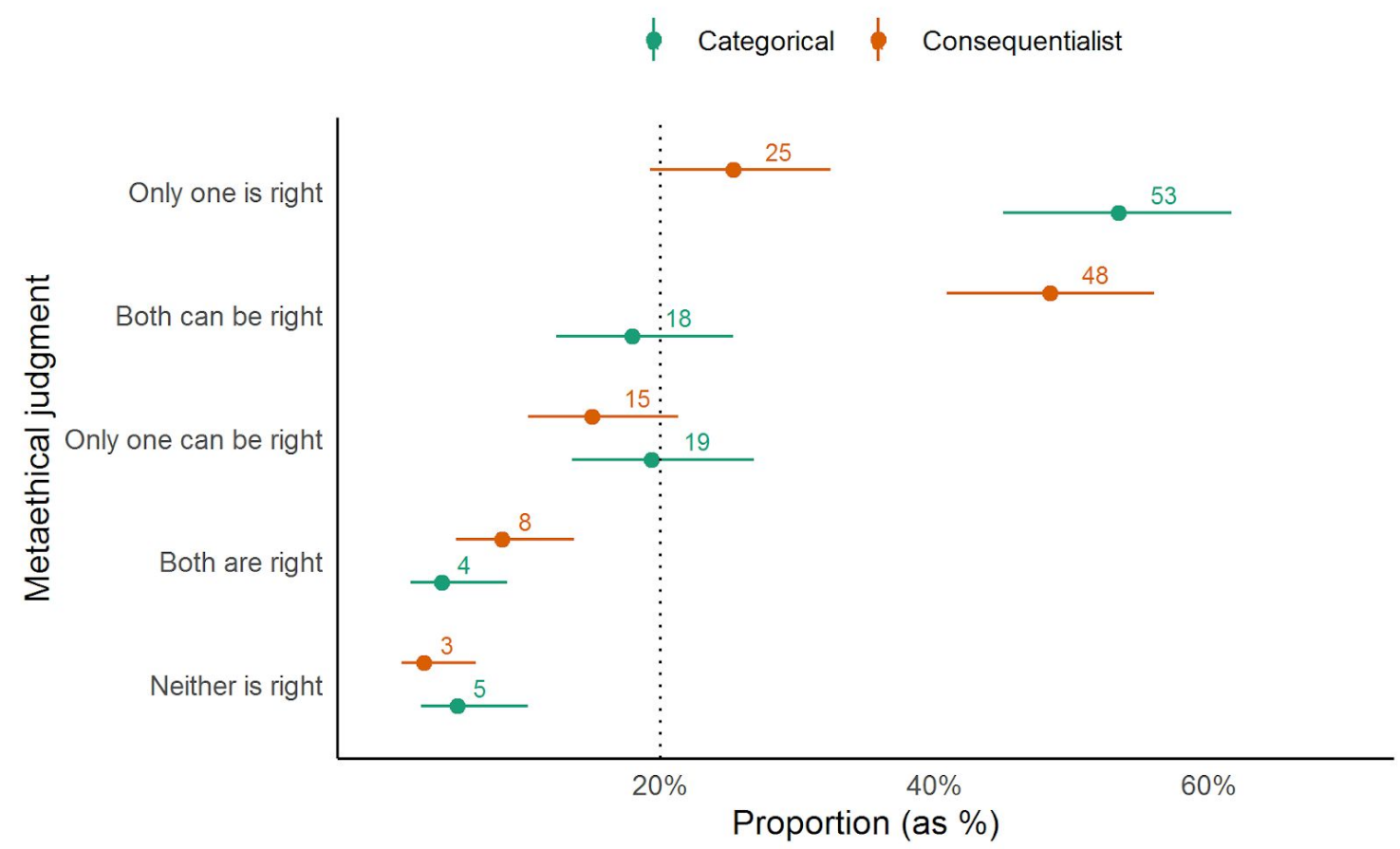

Figure 7. Proportion of consequentialist and categorical justifications by metaethical response option. The $x$-axis displays the percentage of consequentialist justifications (brown) and categorical justifications (green) accompanying each metaethical judgment.

Finally, we conceptually replicated some of our results by employing the folk moral objectivism scale (FMO; Zjilstra 2019), a construct including different dimensions of metaethical beliefs on moral truth.The Spanish translation of the scale showed adequate to strong reliability in its three subscales: Independent Moral Truth, $\alpha=.0 .81$, Universalism, $\alpha=.0 .87$, and Divine Command Ethics, $\alpha=.0 .92$. The Independent Moral Truth subscale, capturing the belief in a mind-independent morality, correlated negatively with the proportion of relativist responses on the disagreement task, $r(299)=-.13, p=.02$. Furthermore, all three subscales negatively predicted the proportion of consequentialist responses: Independent Moral Truth $r(299)=-.16, p=.004$, Universalism $r(299)=$ 
-.14, $p=.01$, Divine Command Ethics $r(299)=-.16, p=.004$. These results provide further evidence that consequentialist normative ethics are linked to various facets of metaethical beliefs.

\section{General Discussion and Conclusions}

In a series of studies we found a robust link between relativist metaethics and consequentialist attitudes, when participants were asked to consider a series of controversial issues in bioethics.

Since Ruth Macklin (1999) called for an enrichment of the vocabulary in the relativism-absolutism debate in bioethics, some water has run under the bridge. Perhaps the dominant view of folk metaethics among moral philosophers in the twentieth century, the uniformity assumption, states that individuals' folk moral judgments ought to be uniform across items: That is, if a person views one particular issue as objectively ethical or unethical, they will also believe that any other ethical controversy will have an objective answer. In our three studies, participants' metaethical attitudes did not obey this uniformity assumption (Gill 2009). Rather, metaethical attitudes represented an independent dimension, but one which closely tracks the intensity of people's moral conviction and the extent to which they perceive the issue in question as consensual or socially divisive. The evidence is now strong that individuals tend to embrace rather diverse metaethical attitudes regarding moral disagreement, depending on the issues at stake (eg. Cova \& Ravat 2008; Pölzler \& Cole-Wright 2020). Thus, we believe that the time is ripe for empirical bioethics to update this assumption.

Less clear, and much more disputed at present, is the question of what form of semantics substitutes the previous unidimensional picture informed by the uniformity assumption. Our data in study 3 do not support the idea that a substantial fraction of the folk embrace a radical subjectivism, where what is morally acceptable or unacceptable is simply determined entirely by either personal or cultural beliefs. For all issues in study 3, participants' median proportion of responses of the strictly subjectivist response 'both are right' was 0 . (Item by item, proportion of "both are right" answers was never higher than 
10\%, 'Medically Assisted Suicide' and 'GMOs' being the issues which invoked these responses the most). Folk incoherentism (Loeb 2008), by which people could project certain metaethical intuitions to moral judgments without the usual logical constraints and sophisticated nuances imposed by professional philosophers, is one strong candidate. Another one is non-exclusionary indexical moral relativism (Beebe 2020), by which lay people can embrace representations of the simultaneous validity of contradictory moral statements, the content of those seemingly contradictory statements being context-sensitive. Contextualism's dependence on what the facts imply for the various parties involved might in principle help explain the close connection with consequentialist thinking that we found, as well as the role of epistemic uncertainty. It can also be noted that, based on our results of study 3 , the characteristic signature of relativist answers might be more aptly described as a refusal of absolutist metaethics ("only one is right") than a rejection of a more principled form of moral objectivism. Thus, another contender could be a form of pluralistic relativism, by which, on certain divisive matters, laypeople can recognize their moral ambivalence (as described by Wong 2009).

Though our studies sought to understand the cognitive mechanisms at play, numerous attempts to consider the role of third variables uncovered limited evidence: whether looking at actively open-minded thinking, cognitive reflection, openness to experience, moral uncertainty, or social desirability. If anything, epistemic uncertainty appeared to share variance with both consequentialism and relativism — which may chart a promising path forward to understanding the cognitive traits that subserve these attitudes toward moral truth and value.

We have corroborated that these effects appear not only at the individual level but especially strongly at the issue level. Although individuals may be more strongly predicted to adopt a consequentialist stance if they chose a relativist solution to the moral disagreement, it is, crucially, those issues that at the societal level invoke an exclusionary answer that can be even more strongly predicted to also elicit non-consequentialist attitudes.

The present research documented a connection between metaethical 
(i.e., second-order) attitudes and the social processes that shape the evolution of bioethical controversies in the public sphere. As such, our findings are congenial with previous evidence indicating that metaethical attitudes can have substantial practical import: resulting in beneficial or nefarious consequences for social cohesion (Viciana et al. 2019). In the present set of studies, we documented a convergent phenomenon, according to which the manner in which citizens conceptualize moral truth and disagreement strongly predicts their openness to consequentialist evidence. Given the high stakes associated with regulating complex and divisive practices in bioethical debates, we believe these findings provide reason to elevate public vigilance around exclusionary metaethical attitudes and their pernicious effects.

\section{References}

- Appel, J. M. 2010. Sex rights for the disabled? Journal of Medical Ethics, 36(3), 152-154.

- Ayars, Alisabeth, and Shaun Nichols. 2020. Rational learners and metaethics: Universalism, relativism, and evidence from consensus. Mind \& Language 35.1: 67-89

- Baron, J. 1995. Myside bias in thinking about abortion. Thinking \& Reasoning, 1(3), 221-235.

- Baron, J. 2006. A decision analysis of consent. The American Journal of Bioethics, 6(3), 46-52.

- Baron, J. 2006. Against Bioethics. Cambridge: MIT Press

- Baron, J. 2008. Thinking and deciding. Cambridge: Cambridge University Press

- Baron, J., Scott, S., Fincher, K., \& Metz, S. E. 2015. Why does the cognitive reflection test (sometimes) predict utilitarian moral judgment (and other things)? Journal of Applied Research in Memory and Cognition, 4(3), 265-284.

- Baron, J. 2019. Actively open-minded thinking in politics. Cognition, 188, 8-18.

- Barrett, R. J., \& Parker, D. B. 2003. Rites of consent: negotiating research participation in diverse cultures. Monash Bioethics Review, 22(2), 9-26.

- Beebe, J. R. 2014. How different kinds of disagreement impact folk metaethical judgments. Advances in experimental moral psychology, 167-87. 
- Beebe J. R. 2015. The empirical study of folk metaethics. Etyka, 12.

- Beebe, J. R. 2020. The Empirical Case for Folk Indexical Moral Relativism. Oxford Studies in Experimental Philosophy, vol. 4. Oxford: Oxford University Press

- Bostrom, N. 2003. Human genetic enhancements: a transhumanist perspective. The Journal of value inquiry, 37(4), 493-506.

- Bradley, P. 1999. Should childhood immunisation be compulsory? Journal of Medical Ethics, 25(4), 330-334.

- Callahan, S., \& Callahan, D. 1984. Abortion: Understanding Differences. Springer

- Casal, P. 2003. Is multiculturalism bad for animals?. Journal of Political Philosophy, 11(1), 1-22.

- Cohen, I. G. 2013. Transplant Tourism: The Ethics and Regulation of International Markets for Organs, The Journal of Law, Medicine \& Ethics, Volume 41, Issue 1, (Spring), 269-285

- Collier-Spruel, L., Hawkins, A., Jayawickreme, E., Fleeson, W., \& Furr, R. M. 2019. Relativism or tolerance? Defining, assessing, connecting, and distinguishing two moral personality features with prominent roles in modern societies. Journal of personality, 87(6), 1170-1188.

- Cova, F., \& Ravat, J. 2008. Sens commun et objectivisme moral: objectivisme 'global' ou objectivisme 'local'? Une introduction par l'exemple à la philosophie expérimentale. Klésis-Revue Philosophique, 9:180-202.

- Dieterle, J. M. 2007. Physician assisted suicide: a new look at the arguments. Bioethics, 21(3), 127-139.

- Di Nucci, E. 2011. Sexual rights and disability. Journal of Medical Ethics, 37(3), 158-161.

- Earp, B. D., Douglas, T., \& Savulescu, J. 2018. Moral neuroenhancement. In L. S. M. Johnson \& K. S. Rommelfanger (Eds.), Routledge handbooks in applied ethics. The Routledge handbook of neuroethics (p. 166-184). Routledge/Taylor \& Francis Group.

- Feltz, A., \& Cokely, E. T. 2008. The fragmented folk: More evidence of stable individual differences in moral judgments and folk intuitions. In Proceedings of the 30th annual conference of the cognitive science society (pp. 1771-1776). Austin, TX: Cognitive Science Society.

- Festing, S., \& Wilkinson, R. 2007. The ethics of animal research: talking point on the use of animals in scientific research. EMBO reports, 8(6), 526-530.

- Fiester, A. 2008. Justifying a presumption of restraint in animal biotechnology research. The American Journal of Bioethics, 8(6), 36-44.

- Frederick, S. 2005. Cognitive reflection and decision making. Journal of Economic perspectives, 19(4), 25-42.

- Gill, M. B. 2009. "Indeterminacy and Variability in Meta-Ethics." Philosophical Studies, 145, 215-234.

- Glannon, W. 2008. The case against conscription of cadaveric organs for transplantation, Cambridge Quarterly of Healthcare Ethics, Volume 17, Issue 3 (July), 330-336. 
- Goodwin, G. P., \& Darley, J. M. 2008. The psychology of meta-ethics: Exploring objectivism. Cognition, 106(3), 1339-1366.

- Goodwin, G. P., \& Darley, J. M. 2010. The perceived objectivity of ethical beliefs: Psychological findings and implications for public policy. Review of Philosophy and Psychology, 1(2), 161-188.

- Goodwin, G. P., \& Darley, J. M. 2012. Why are some moral beliefs perceived to be more objective than others?. Journal of Experimental Social Psychology, 48(1), 250-256.

- Graziano, W. G., Jensen-Campbell, L. A., \& Hair, E. C. 1996. Perceiving interpersonal conflict and reacting to it: the case for agreeableness. Journal of personality and social psychology, 70(4), 820.

- Graziano, W. G., \& Tobin, R. M. 2002. Agreeableness: Dimension of personality or social desirability artifact?. Journal of personality, $70(5)$, 695-728.

- Gutmann, A., \& Moreno, J. D. 2019. Everybody Wants to Go to Heaven But Nobody Wants to Die: Bioethics and the Transformation of Health Care in America. New York: Liveright Publishing.

- Hannikainen, I. R., Miller, R. M., \& Cushman, F. A. 2017. Act versus impact: Conservatives and liberals exhibit different structural emphases in moral judgment. Ratio, 30(4), 462-493

- Hendrix, K. S., Sturm, L. A., Zimet, G. D., \& Meslin, E. M. 2016. Ethics and childhood vaccination policy in the United States. American journal of public health, 106(2), 273-278.

- Heiphetz L., \& Young L. L., Can only one person be right? The development of objectivism and social preferences regarding widely shared and controversial moral beliefs. Cognition, 2017, 167, 78-90. pmid:27260661

- Hippen, B. E. 2005. In Defense of a Regulated Market in Kidneys from Living Vendors The Journal of Medicine and Philosophy Volume 30, Issue 6, 2005, 593-626.

- Jensen-Campbell, L. A., \& Graziano, W. G. 2001. Agreeableness as a moderator of interpersonal conflict. Journal of personality, 69(2), 323-362.

- John, O. P., Donahue, E. M., \& Kentle, R. L. 1991. Big Five Inventory (BFI) [Database record]. APA PsycTests.

- Juengst, E, Fossel, M. (2000). The Ethics of Embryonic Stem Cells-Now and Forever, Cells Without End. JAMA. 284(24), 3180-4.

- Kass, L. R., \& Lund, N. 1996. Physician-assisted suicide, medical ethics and the future of the medical profession. Duq. L. Rev., 35, 395.

- Kirby, J. 2014. Transnational gestational surrogacy: Does it have to be exploitative?. The American Journal of Bioethics, 14(5), 24-32.

- Loeb, D. 2008. Moral incoherentism: How to pull a metaphysical rabbit out of a semantic hat, In: Moral psychology: The cognitive science of morality: Intuition and diversity, 2, 355-85.

- Macklin, R. 1999. Against relativism: cultural diversity and the search for ethical universals in medicine. Oxford: Oxford University Press, USA. 
- Mihailov, E., Hannikainen, I. R., Cova, F., \& Rodríguez López, B. More pills, fewer skills: Cognitive enhancement undermines merit during competition, in prep.

- Moreno, J. D. (2005). The end of the great bioethics compromise. Hastings Center Report, 35(1), 14-15.

- Nelson, L. J., \& Meyer, M. J. 2005. Confronting deep moral disagreement: The President's Council on Bioethics, moral status, and human embryos. The American Journal of Bioethics, 5(6), 33-42.

- Orfali, K., \& Chiappori, P. A. 2014. Transnational gestational surrogacy: exploitative or empowering?. The American Journal of Bioethics, 14(5), 33-34.

- Outram, S. M. 2012. Ethical considerations in the framing of the cognitive enhancement debate. Neuroethics, 5(2), 173-184.

- Pennycook, G., Cheyne, J. A., Barr, N., Koehler, D. J., \& Fugelsang, J. A. 2014. The role of analytic thinking in moral judgements and values. Thinking \& reasoning, 20(2), 188-214.

- Piazza, J., \& Landy, J. 2013. "Lean not on your own understanding": belief that morality is founded on divine authority and non-utilitarian moral thinking. Judgment and Decision making, 8(6), 639-661.

- Pölzler, T., \& Wright, J. C. 2020. Anti-realist pluralism: A new approach to folk metaethics. Review of Philosophy and Psychology, 11(1), 53-82.

- Rose, D., \& Nichols, S. 2019. From punishment to universalism. Mind \& Language, 34(1), 59-72.

- Russell, A. W., \& Sparrow, R. 2008. The case for regulating intragenic GMOs. Journal of Agricultural and Environmental Ethics, 21(2), 153-181.

- Singer, P. 2003. Voluntary euthanasia: a utilitarian perspective. Bioethics, 17(5-6), 526-541.

- Schmidt, M. F., Gonzalez-Cabrera, I., \& Tomasello, M. 2017. Children's developing metaethical judgments. Journal of Experimental Child Psychology, 164, 163-177.

- Sedikides, C., \& Gebauer, J. E. 2010. Religiosity as self-enhancement: A meta-analysis of the relation between socially desirable responding and religiosity. Personality and Social Psychology Review, 14(1), 17-36.

- Simonsohn, U. 2018. Two lines: A valid alternative to the invalid testing of U-shaped relationships with quadratic regressions. Advances in Methods and Practices in Psychological Science, 1(4), 538-555.

- Sparrow, R. 2019. Yesterday's child: How gene editing for enhancement will produce obsolescence-and why it matters. The American Journal of Bioethics, 19(7), 6-15.

- Spital, A. Taylor, J. S. 2007. Routine recovery of cadaveric organs for transplantation: Consistent, fair, and life-saving. Clinical Journal of the American Society of Nephrology, 2, 300-3

- Stanovich, K. E., \& West, R. F. 1997. Reasoning independently of prior belief and individual differences in actively open-minded thinking. Journal of Educational Psychology, 89(2), 342.

- Toft, K. H. 2012. GMOs and global justice: applying global justice theory 
to the case of genetically modified crops and food. Journal of Agricultural and Environmental Ethics, 25(2), 223-237.

- Tooley T, Wolf-Devine, C., Devine P. E., Jaggar A. M. 2009. Abortion: Three Perspectives. Oxford: Oxford University Press

- Young, L., \& Durwin, A. J. 2013. Moral realism as moral motivation: The impact of meta-ethics on everyday decision-making. Journal of Experimental Social Psychology, 49(2), 302-306.

- Velleman, J. D. 1992. Against the right to die. In The Journal of Medicine and Philosophy: A Forum for Bioethics and Philosophy of Medicine. Vol. 17, No. 6, pp. 665-681

- Viciana, H., Hannikainen, I. R., \& Gaitán, A. 2019. The dual nature of partisan prejudice: Morality and identity in a multiparty system. PloS one, 14(7).

- Wolff, F. (2018). The Ethical Status of the Bull in Corrida. The Philosophical Journal of Conflict and Violence, Vol. II, Issue 2

- Wong, D. B. 2009. Natural moralities: A defense of pluralistic relativism. Oxford: Oxford University Press.

- Zijlstra, L. 2019. Folk moral objectivism and its measurement. Journal of Experimental Social Psychology, 84, 103807.

\section{Acknowledgements}

We would like to thank Jonathan Baron and Antonio Gaitán for providing valuable feedback at different points of this project. We would also like to thank Sara Pasadas del Amo, Juan Antonio Domínguez, Rodrigo Díaz, David Teira, Carissa Véliz, Rafael Cejudo, Miguel Moreno, Antonio Diéguez, Jesús Vega, Fernando Broncano Berrocal, Fernando Aguiar and Manolo de Pinedo for helpful comments or assistance at various points.

\section{Author contributions}

HV: Conception and design; Data collection; Data curation; Analysis and interpretation of data; Visualization; Writing IvarRH: Analysis and interpretation of data; Visualization; Writing DR-A: Conception and design; Writing

\section{Funding details}

The present work has benefitted from funding by Victor Grifols i Lucas Foundation and 
the Ministerio de Ciencia e Innovación under grants FFI2015-67569-C2-2-P, FFI2017-88913-P, and RTI2018-098882-B-100. The funders had no role in study design, data collection and analysis, decision to publish, or preparation of the manuscript.

\section{Conflicts of interest}

None disclosed. 